\title{
MATHEMATICAL DEVELOPMENT PROGRAM FOR CALCULATION OF FATTY ACID COMPOSITION BLEND OF VEGETABLE OILS
}

\author{
Tatiana Belemets \\ Department of Technology of milk and dairy products \\ Higher Educational Establishment of Ukraine «National University of Food Technologies» \\ 68 Volodymyrska str., Kyiv, Ukraine, 01033 \\ Tatiana_Belemets@i.ua \\ Natalia Yushchenko \\ Department of Technology of milk and dairy products \\ Higher Educational Establishment of Ukraine "National University of Food Technologies» \\ 68 Volodymyrska str., Kyiv, Ukraine, 01033 \\ yunm_nuft@ukr.net \\ Alexei Lobok \\ Department of automation and intelligent control systems \\ Higher Educational Establishment of Ukraine «National University of Food Technologies» \\ 68 Volodymyrska str., Kyiv, Ukraine, 01033 \\ apl_apl@ukr.net \\ Irina Radzievskaya \\ Department of Technology of fats and perfumery-cosmetic products \\ Higher Educational Establishment of Ukraine «National University of Food Technologies》 \\ 68 Volodymyrska str., Kyiv, Ukraine, 01033 \\ logos2007@ukr.net \\ Tatiana Polonskaya \\ Department of Technology of fats and perfumery-cosmetic products \\ Higher Educational Establishment of Ukraine "National University of Food Technologies» \\ 68 Volodymyrska str., Kyiv, Ukraine, 01033 \\ tanjy@ukr.net
}

\begin{abstract}
The method of solution of the problem of polyunsaturated fatty acids (PUFA) lack in milk products is offered in the work. It is offered to create the milk-containing products (sour cream product) with adjusted fatty acid composition. The possibility of replacement of the mass part of milk fat ( $50 \%$ ) by the blend of natural vegetable oils was studied. For the solution of this problem the program within MatLab mathematical package was elaborated. The recommended fatty acids (FA) ratio [3] is selected as optimization parameter. The optimized blend was created using the elaborated program. The data, received by mathematical calculations, were experimentally proved using the method of gas-liquid chromatography [7]. On the based of the results, received at the studies, it can be stated, that $50 \%$ replacement of mass part of fat (m.p.f.) in milk products (sour cream product) by elaborated blend, allows partially adjust its FA composition.

Keywords: natural vegetable oils, blend by mathematical method, milk-containing products, optimization of fatty acid composition, gas-liquid chromatography.

DOI: $10.21303 / 2504-5695.2016 .00192$

(C) Tatiana Belemets, Natalia Yushchenko, Alexei Lobok, Irina Radzievskaya, Tatiana Polonskaya
\end{abstract}

\section{Introduction}

The modern food products must fill organism with all essential nutriments that can come with food only [1].

According to the formula of balanced nutrition [2], the day need of adult person in vegetable oil is $20 \ldots 30 \mathrm{~g} / \mathrm{day}$, at the same time the PUFA percent of the general FA quantity is $12 \ldots 30 \%$. 
PUFA $\omega-6: \omega$ ratio is 3 for healthy human $-9 \ldots 10: 1$, in the cases of metabolism pathologies $-5: 1 \ldots 3: 1$ [2]. According to the data of nutritionists of NDI of food, RAMN, for today Ukrainian population consumes PUFA of $\omega-6: \omega-3$ classes in ratio - 30:1 [3]. It also must be noted, that the PUFA lack in everyday ration provokes the decrease of immunity, causes the disorder of the nervous system activity, increases the risk of severe diseases [3]. According to [4] (with reference to the WHO experts) fat component of everyday ration have a ratio UFA:MUFA:PUFA, as 1:1:1. At that such composition of the "ideal" lipid is the basic one for elaboration of the norms of physiological needs of population in basic food substances and energy.

But there is no natural vegetable oil, balanced by FA composition. In this connection the studies, directed on creation of blends on the base of natural vegetable oils with balanced FA composition, are topical.

For optimization of oils FA composition by blend the different calculating methods are used. The method of "golden section" and other ones are especially widespread [5, 6]. The authors [2] offered to make calculations of balanced blends using MatCad program package by the solution of the system of equations with three variables. But this method of calculation provides creation of blend using three variables only.

Taking into account all aforesaid arguments, the article offers the specially created program for creation of experimental sample of blend, based on three oils and its further usage for correction of FA composition of milk products. The correspondence of received calculation data to the real FA quantity and ratio in composition of experimental sour cream product (milk-containing product) was proved by chromatographic method.

The most widespread method of chromatographic analysis is the one of gas chromatography $[7,8]$. The methodology of interpretation of chromatograms, received at FA analysis is described in details in the article [9]. At the same time some difficulties must be taken into account at using this method (FA are badly divided on capillary columns with non-polar immovable phase (NP)). The special capillary columns were elaborated for their better distribution, but under such conditions the differences between acids by the quantity composition are also appeared that, in its turn, leads to the masking of peaks and is a disadvantage of gas chromatography. The most modern method is the one of capillary gas-liquid chromatography (best for multi-component analysis). Its distinctive features are expressiveness, sensitivity, high exactness. The gas-liquid method is most effective at distribution of substances, related to the same class $[10,11]$. That is just why its use for the more exact FA analysis of the fatty phase of food products is most expedient.

\section{Materials and Methods}

Vegetable oils were selected for the addition to the sour cream, based on organoleptic parameters, compatibility with milk base and between each other. The grounding of blend composition of the vegetable oils was carried out based on the modern notion about the role of fats and their components in human nutrition and rational ratio of the separate groups of fatty acids. The important factors at the choice of vegetable oils for blend are their technological properties, price policy and territorial prevalence. Taking into account all named requirements, the authors have chosen three natural vegetable oils: corn, rape and walnut ones (the two last are not refined and deodorized). The fatty acid composition of chosen and some other oils is presented in the Table $\mathbf{1 .}$

The corn oil is more accessible in its purpose direction and can serve as the source of PUFA, which overwhelming majority belongs to the group $\omega-6$. According to its organoleptic parameters, corn oil has the bright yellow color and pleasant taste. The corn oil, chosen for the studies (producer: «Agrosilprom» Group, Ukraine, Dnipro region, v. Gorianivske; brand «Golden Kings of Ukraine») is not refined and not deodorized (so, the processing by acids is excluded). At the production of this oil the processing by alkali and extraction by chemical solvents was not applied, any chemical ingredients, taste additives, preservatives and coloring agents were not used. Due to that the molecules of such oil are kept in the native state.

The lack of fatty acids of $\omega-3$ group can be compensated by adding rape oil (producer: "Kharkivnaturproduct" Ltd, Ukraine, city Kharkiv; brand "Oil traditions"; non-refined and non-deodorized) that also has the low cost price but is characterized with rather specific organolep- 
tic properties. Due to the high content of MUFA and PUFA, the use of this oil for creation of blend, optimized by its fatty acid composition, is rational because just the increase of percent of essential fatty acids in milk products composition is necessary.

Table 1

Comparative characteristic of the fatty acid composition of vegetable oils and milk fat [12]

\begin{tabular}{cccccccc}
\hline $\begin{array}{c}\text { Content of separate fatty } \\
\text { acids groups, \% }\end{array}$ & Corn & Rape & Walnut & Sesame & Soy & $\begin{array}{c}\text { Type of vegetable oil } \\
\text { Ompkin }\end{array}$ & Milk fat * \\
\hline Saturated & 11.06 & 6.86 & 8.2 & 15.33 & 15.55 & 19.8 & 64.81 \\
Monounsaturated & 27.87 & 65.32 & 15.84 & 39.27 & 21.34 & 21.58 & 29.76 \\
Polyunsaturated & 60.11 & 27.81 & 74.96 & 45.08 & 61.4 & 58.54 & 5.42 \\
Totally including: & 99.04 & 99.99 & 99 & 99.7 & 98.3 & 99.92 & 99.00 \\
$\omega-6$ & 59.99 & 18.67 & 61.36 & 44.72 & 55.67 & 58.4 & 3.4 \\
$\omega-3$ & 0.12 & 9.14 & 13.6 & 0.36 & 5.73 & 0.14 & 0.2 \\
$\omega-6: \omega-3$ & $499.9: 1$ & $2.04: 1$ & $4.5: 1$ & $124.2: 1$ & $9.7: 1$ & $417.1: 1$ & $17: 1$
\end{tabular}

Note: * - data of own studies

On the base of organoleptic assessment of the possibility of combination of walnut oil (producer: «Agrosilprom" Group, Ukraine, Dnipro region, v. Gorianivske; brand «Golden Kings of Ukraine») with other vegetable oils, it was concluded, that the addition of this oil allows give the pleasant nut smack and scent to the blend (even in small doses). These organoleptic characteristics are the weighty arguments for the inclusion of walnut oil in blend. It is connected with the fact that its pleasant taste and scent completely replace the specific organoleptic properties of rape oil.

It is also worth noting, that three chosen oils have not only the high content of deficit polyunsaturated fatty acids, according to preliminary studies of organoleptic parameters, they are combined with milk base and between each other that allows recommend them for blend and further use in milk products technology.

So, taking into account all aforesaid arguments, 3 natural vegetable oils have been chosen for the blend creation: corn, rape and walnut.

The technology of sour cream product has been chosen as the object of experimental studies. The improvement of its physical-chemical properties allows increase the food value of ready products, save the raw material resources and enrich it with the complex of irreplaceable nutrients: mono- and polyunsaturated fatty acids, vitamins and so on.

The subject: normalized cream (taking into account the further addition of vegetable oils blend) fermented by the pure sour-milk cultures (Lactococcus lactis subsp. lactis, Lactococcus lactis subsp. diacetylactis, Lactococcus lactis subsp. cremoris та Streptococcus salivarius subsp. thermophilus), cow milk cream with mass part of fat $20 \%$, vegetable natural oils: corn, rape and also walnut.

The aim of our studies is epy elaboration of blend, based on the natural vegetable oils with optimized FA composition and its further use as the substitute of milk fat in technology of milk-containing products manufacturing.

On the base of the literary review, the mathematical calculations for creation of balanced blend using natural vegetable oils are recommended to be based [3] on $\omega-6: \omega-3$ ratio that must be from $-6: 1$ to $10: 1$, at that the ratio of groups UFA:MUFA:PUFA must be maximally approximated to $1: 1: 1$. Taking into account the fact that the set problem is aimed at the synchronous optimization of the several conflicting objective functions in the distinctly set determination area (correction of three main groups of fatty acids - UFA:MUFA:PUFA and essential fatty acids of $\omega-6: \omega-3$ groups in the composition of elaborated blend), the most rational solution of this problem is the construction of mathematical model with its further optimization within MatLab environment. The necessary variable of quantity of all chosen oils (corn, rape, walnut) and the constant of milk fat percent $-50 \%$ is calculated using MatLab environment.

In correspondence with aforesaid, let's give the formalized description of the problem of elaborating blend with optimized fatty acid composition, based on the chosen vegetable oils. 
Let's consider the following matrix of experimental data.

$$
Z=\left(\begin{array}{cccc}
z_{11} & z_{12} & \ldots & z_{1 n} \\
z_{21} & z_{22} & \ldots & z_{2 n} \\
\ldots & \cdots & \cdots & \cdots \\
z_{m 1} & z_{m 2} & \ldots & z_{m n}
\end{array}\right)=\left\{z_{i j}\right\}_{i=1, j=1}^{m, n},
$$

where $\mathrm{i}$ - the sequence number of fatty acid (line), $\mathrm{j}$ - sequence number of vegetable oil (column) in the table of experimental data, $z_{i j}$ - quantity of $i$ fatty acid in $j$ vegetable oil, $n$ - general number of vegetable oils, $\mathrm{m}$ - general number of fatty acids in the table of experimental data.

For the grouping (separation, selection) of the three main groups of fatty acids - UFA, MUFA, PUFA and essential fatty acids groups $\omega-6$ and $\omega-3$ in z matrix, let's form arrays (vectors) of indices for each group

$$
\alpha_{\mathrm{k}}=\left(\mathrm{r}_{1}^{(\mathrm{k})}, \mathrm{r}_{2}^{(\mathrm{k})}, \ldots, \mathrm{r}_{\mathrm{n}_{\mathrm{k}}}^{(\mathrm{k})}\right) \in \mathrm{N}^{\mathrm{n}_{\mathrm{k}}}, \mathrm{k}=1,2, \ldots, 1
$$

where $r_{i}^{(k)}$ - number of fatty acid (number of line) (number of line) in matrix $z$, included in k group of fatty acids, $\mathrm{N}^{\mathrm{n}_{\mathrm{k}}}$ - set of $\mathrm{n}_{\mathrm{k}}$ - measuring space, consisted of $\mathrm{n}_{\mathrm{k}}$ - measuring vectors of natural number, 1 - general number of fatty acids groups in $\mathrm{z}$ matrix of experimental data $(\mathrm{l}=5)$. In other words, $\alpha_{1}, \alpha_{2}, \alpha_{3}$ - are the arrays of indices (lines) of fatty acids, correspondingly, UFA, MUFA and PUFA in matrix $z$, and $\alpha_{4}$ and $\alpha_{5}$ - arrays of indices of essential fatty acids of the groups $\omega-6$ and $\omega-3$ respectively. by formula:

Then let's determine the matrix of fatty acids $A=\left\{a_{k j}\right\}_{k=1, j=1}^{1, n}$, which elements are calculated

$$
\mathrm{a}_{\mathrm{kj}}=\sum_{\substack{\mathrm{i}=1 \\ \mathrm{i} \in \alpha_{\mathrm{k}}}}^{\mathrm{m}} \mathrm{z}_{\mathrm{ij}}, \mathrm{k}=1,2, \ldots, 1, \mathrm{j}=1,2, \ldots, \mathrm{n},
$$

where $\alpha_{k}$ - array of indices of $k$ group of fatty acids, determined by the ratio (2). Let's note, that at the content level $a_{k j}$ is a number of fatty acids of $k$ group in $j$ vegetable oil.

As far as not all vegetable oils from the $\mathrm{z}$ matrix are used for the balanced blends creation, but only its certain subset, let's consider the one more vector of indices of selected vegetable oils for the balanced blend formation $-\beta=\left(\beta_{1}, \beta_{2}, \ldots, \beta_{\mathrm{p}}\right)$, where $\beta_{\mathrm{i}}$ - index of selected vegetable oil (column number) in $\mathrm{z}$ matrix and $\mathrm{p}$ - general number of oils, selected for blend. Let's note, that $\beta_{\mathrm{p}}$ (the last element of $\beta$ vector) - is the number of milk oil in $z$ matrix.

Let's form the vectors-columns that correspond to the selected set of oils for blend of A matrix

$$
c_{k}=\left(\begin{array}{c}
a_{1 \beta_{k}} \\
a_{2 \beta_{k}} \\
\ldots \\
a_{1 \beta_{k}}
\end{array}\right), k=1,2, \ldots, p .
$$

At the same time let's mark i oil share in general mixture $\left(0 \leq \mathrm{x}_{\mathrm{i}} \leq 1\right)$ as $\mathrm{x}_{\mathrm{i}}$. It is obvious, that $\sum_{i=1}^{p} x_{i}=1$. As far as the milk oil must be $50 \%$ of the mixture that is $x_{p}=0.5$ so $\sum_{i=1}^{p-1} x_{i}=0.5$.

Then let's construct the vector-function as

$$
g(x)=c_{1} x_{1}+c_{2} x_{2}+\ldots+c_{p-1} x_{p-1}+0.5 c_{p}=\sum_{i=1}^{p-1} c_{i} x_{i}+0.5 c_{p}
$$

where

$$
\mathrm{x}=\left(\mathrm{x}_{1}, \mathrm{x}_{2}, \ldots, \mathrm{x}_{\mathrm{p}-1}\right),
$$




$$
g(x)=\left(\begin{array}{c}
g_{1}(x) \\
g_{2}(x) \\
\ldots \\
g_{1}(x)
\end{array}\right) .
$$

Let's note, that the function $\mathrm{g}_{\mathrm{k}}(\mathrm{x})(\mathrm{k}=1.2, \ldots, 1)$ describes the general number of fatty acids in the mixture that are related to the $\mathrm{k}$ group of fatty acids $(\mathrm{k}=1-\mathrm{UFA}, \mathrm{k}=2-$ MUFA, $\mathrm{k}=3$ - PUFA, $\mathrm{k}=4-\omega-6, \mathrm{k}=5-\omega-3)$ at the set share vector of $\mathrm{x}$ oils in the mixture. Let's also note that the function $g_{k}(x)$ can be presented as

$$
\begin{aligned}
& \mathrm{g}_{\mathrm{k}}(\mathrm{x})=\mathrm{a}_{\mathrm{k} \beta_{1}} \mathrm{x}_{1}+\mathrm{a}_{\mathrm{k} \beta_{2}} \mathrm{x}_{2}+\ldots+\mathrm{a}_{\mathrm{k} \beta_{p-1}} \mathrm{x}_{\mathrm{p}-1}+ \\
& +0.5 \mathrm{a}_{\mathrm{k} \beta_{\mathrm{p}}}=\sum_{\mathrm{i}=1}^{\mathrm{p}-1} \mathrm{a}_{\mathrm{k} \beta_{\mathrm{i}}} \mathrm{x}_{\mathrm{i}}+0.5 \mathrm{a}_{\mathrm{k} \beta_{\mathrm{p}}} .
\end{aligned}
$$

Since $\sum_{\mathrm{i}=1}^{\mathrm{p}-1} \mathrm{x}_{\mathrm{i}}=0.5$, the dimensionality of $\mathrm{x}$ vector can be reduced, so the dimensionality of problem can also reduced by unit, and the one of coordinates of this vector can be determined through the all other. For example, let's determine the coordinate $x_{p-1}$

$$
\mathrm{x}_{\mathrm{p}-1}=0.5-\sum_{\mathrm{i}=1}^{\mathrm{p}-2} \mathrm{x}_{\mathrm{i}} .
$$

So, taking into account (6), vector-function (5) can be presented as

$$
\begin{aligned}
& g(x)=\sum_{i=1}^{p-2} c_{i} x_{i}+c_{p-1}\left(0.5-\sum_{i=1}^{p-2} x_{i}\right)+0.5 c_{p}= \\
& =\sum_{i=1}^{p-2}\left(c_{i}-c_{p-1}\right) x_{i}+0.5\left(c_{p-1}+c_{p}\right)
\end{aligned}
$$

where vector $\mathrm{x}$ has now the dimensionality $\mathrm{p}-2$, and

$$
\sum_{i=1}^{p-2} x_{i} \leq 0.5, \quad 0 \leq x_{i} \leq 0.5, \quad i=1,2, \ldots, p-2 .
$$

According to the problem setting, the ratio of the main groups of fatty acids UFA:MUFA:PUFA can be maximally approximated to 1:1:1, and the ratio of essential fatty acids $\omega-6: \omega-3$ must be from 6:1 to 10:1. It means that the aim of research can be described by the following criteria functions

$$
\begin{aligned}
& f_{1}(x)=\left(\frac{g_{1}(x)}{g_{2}(x)}-1\right)^{2}, f_{2}(x)=\left(\frac{g_{1}(x)}{g_{3}(x)}-1\right)^{2}, \\
& f(x)=\left(\frac{g(x)}{g(x)}-1\right), f_{4}(x)=\left(\frac{g_{4}(x)}{g_{5}(x)}-q\right)^{2},
\end{aligned}
$$

where $\mathrm{q}=6,7,8,9,10$.

The synchronous minimization of functions (8) on the set of admissible solutions

$$
\Omega=\left\{\mathrm{x}: \mathrm{x}=\left(\mathrm{x}_{1}, \mathrm{x}_{2}, \ldots, \mathrm{x}_{\mathrm{p}-2}\right) ; 0 \leq \mathrm{x}_{\mathrm{i}} \leq 0.5, \mathrm{i}=1,2, \ldots, \mathrm{p}-2 ; \sum_{\mathrm{i}=1}^{\mathrm{p}-2} \mathrm{x}_{\mathrm{i}} \leq 0.5\right\}
$$

gives a possibility to receive blend with optimized fatty acid composition. 
Thus, let's come to the following problem of multi-criteria optimization - to determine the optimal vector $\mathrm{x}^{*} \in \mathrm{R}^{\mathrm{p}-2}\left(\mathrm{R}^{\mathrm{p}-2}-\right.$ Euclid space of dimensionality $\left.\mathrm{p}-2\right)$, that provides the accomplishment of the following condition

$$
x^{*}=\arg \min _{x \in \Omega} f(x)
$$

where the set $\Omega$ is set by the ratio (9), and $\mathrm{f}(\mathrm{x})$ - vector criterion of optimality of the type

$$
f(x)=\left(\begin{array}{l}
f_{1}(x) \\
f_{2}(x) \\
f_{3}(x) \\
f_{4}(x)
\end{array}\right),
$$

which components are determined by the formulas (8).

The method of successive minimization of concessions was used for the solution of optimization problem (10). According to it, the problem of multi-criteria optimization is reduced to the one of nonlinear programming

$$
\min _{\gamma \in \mathrm{R}^{1}, \mathrm{x} \in \Omega} \gamma
$$

with limitations

$$
f_{i}(x) \leq w_{i} \gamma, \quad i=1,2,3,4,
$$

where $\mathrm{w}_{\mathrm{i}}$ - the set weight multipliers that determine the importance degree of scalar criteria $\mathrm{f}_{\mathrm{i}(\mathrm{x})}$, and $\gamma$-artificially introduced additional parameter of optimization (specific concession of criteria).

On the base of this method the program in the environment of mathematical package «MatLab» was elaborated and used at calculating experiments. Several results of calculating experiments at $\mathrm{q}=6,8,10$ are presented below in the Table 2 .

Table 2

The results of optimal fatty acids composition at the acids $\omega-6$ and $\omega-3$ ratio

SF:MUFA:PUFA ratio, \%

1.2:1,1:1

Name of the separate fatty acids group
1.3:1.3:1

1.4:1.4:1

$$
\omega-6: \omega-3
$$

8:1

10:1

$6: 1$

36.55

36.77

36.94

MUFA

34.25

36.00

37.28

PUFA

29.02

27.00

25.51

The received numerical data of optimized blend, based on the natural vegetable oils, were verified by the method of gas-liquid chromatography on chromatograph Hewlett Packard HP-6890 (Producer: Agilent Technologies Inc, Hewlett-Packard Inc, USA) Fig. 1. 
The experimental samples were the sample "A" (sour cream product) with $50 \%$ replacement of milk fat in the composition of sour-milk base by created blend and the sample "B" - standard (sour cream). The calculated blend with optimization of criteria of UFA: MUFA:PUFA, as 1.2:1.1:1 and $\omega-6: \omega-3$ as $6: 1$ was used for experiment. The general mass part of fat of the samples «A» and «B» is $20 \%$. The sour cream with mass part of the fat $20 \%$ was used as a control. The experimental samples were used on the Fig. 2.

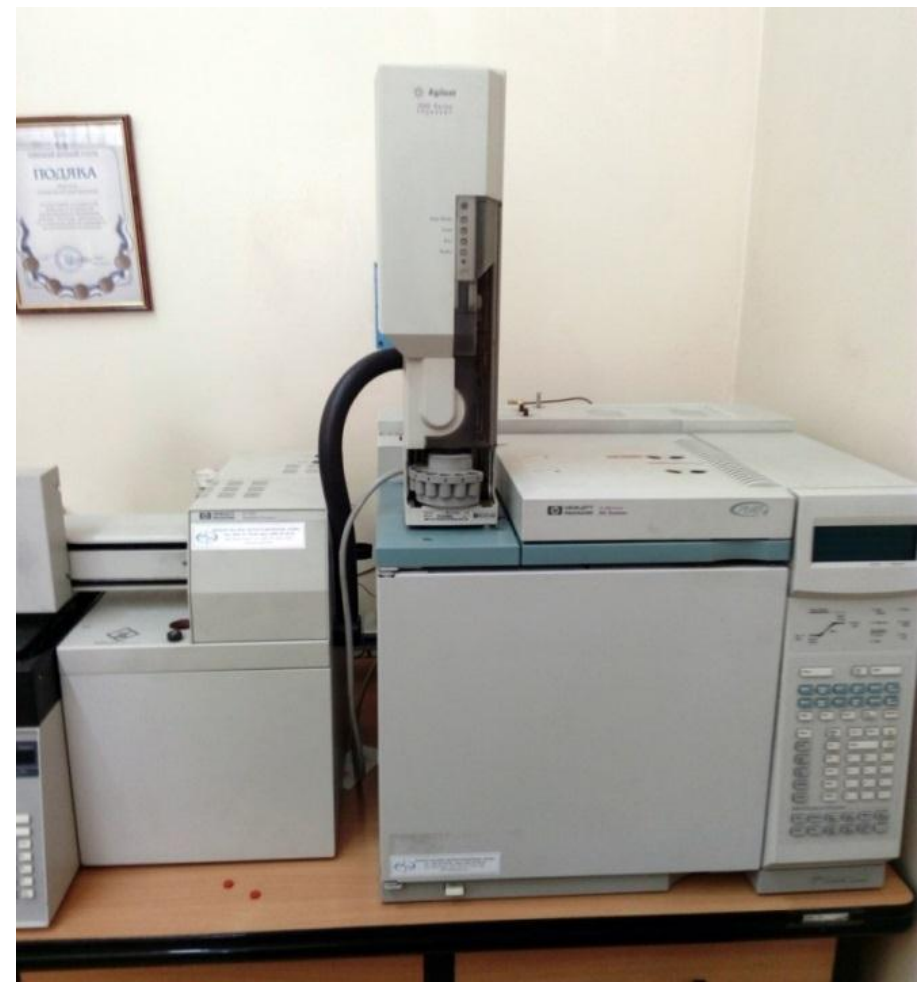

Fig. 1. Gas-liquid chromatograph

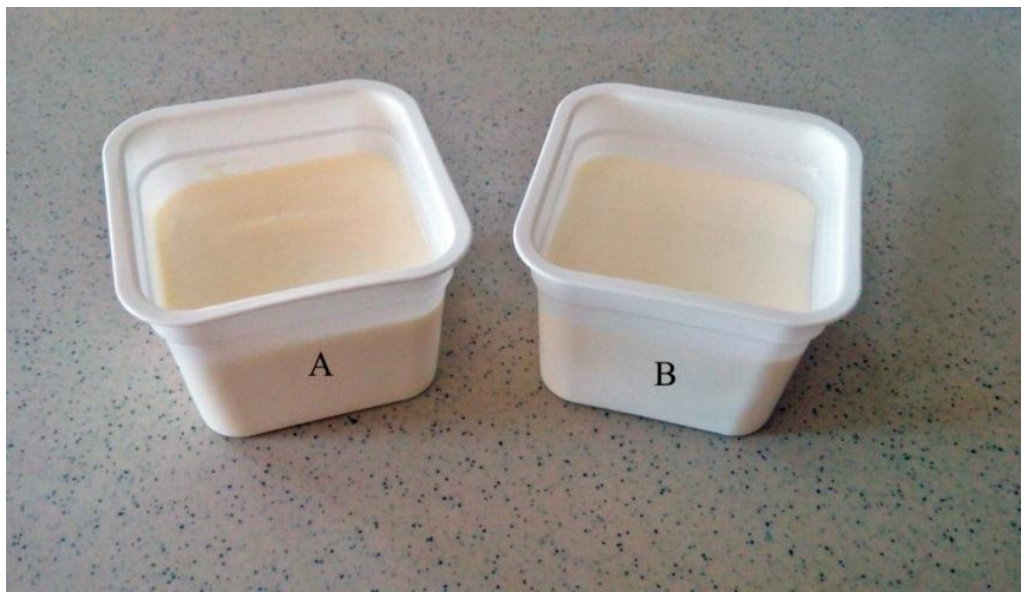

Fig. 2. Experimental samples of the products: A - sour cream product with $50 \%$ replacement of milk fat by elaborated blend of the fat oils; B - sour cream (standard)

The detailed results of analysis of fatty acid composition of the studied sample of the product «A» by the method of gas-liquid chromatography are presented in the Table 3. 
Table 3

The results of fatty acid composition of the studied sample of the product «A», received by the method of gas-liquid chromatography

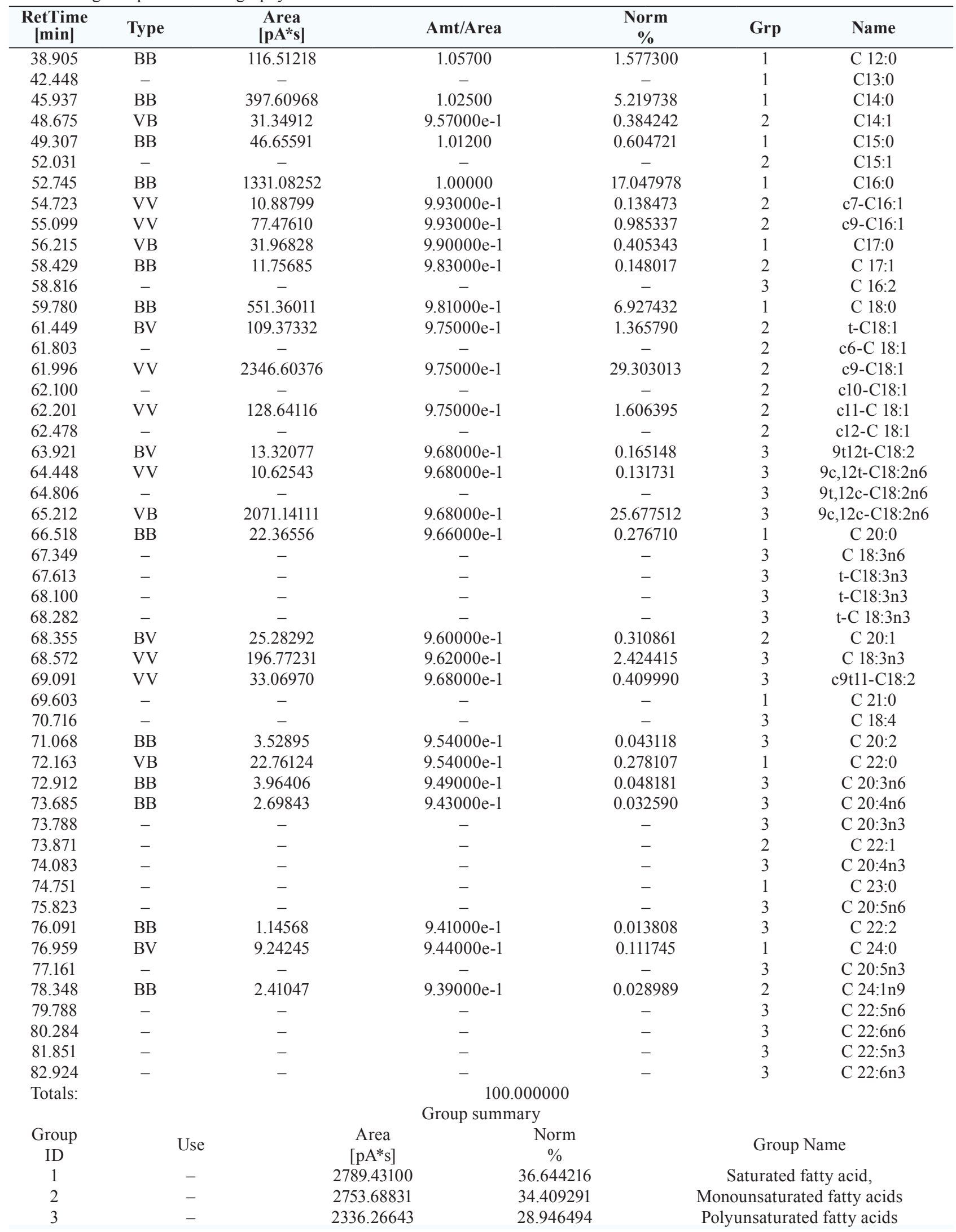




\section{Results}

The experimental sample of the sour cream product "A" (with m.p.f. $20 \%$ ) has been chosen for correction of the fat component; sour cream (with m.p.f. $20 \%$ ) was used as the standard "B". The possibility of maximal $50 \%$ replacement of the milk fat in sour cream product "A: by elaborated blend of natural vegetable oils was experimentally established.

According to the results of scientific studies, it was established, that FA composition of the sample «A» is more balanced (UFA - 36.64; MUFA - 34.40; PUFA - 28.94) as opposite to the standard «B» $(\mathrm{UFA}-64.81$; MUFA - 29.76; PUFA - 5.42). Such grounded changes of indices are connected with $50 \%$ replacement of the milk fat by optimized blend of vegetable oils.

Comparing the results of FA analysis of the sample «A», received by the method of gas-liquid chromatography and with the help of program (prognosticated ones), we can observe the insignificant inclinations, near $1 \%$. The difference does not exceed the admissible $5 \%$ of error and is argued: the error the device indications and also the season variations of the vegetable oils FA composition indices.

The number and ratio of PUFA classes $\omega-6: \omega-3$, for «A» $-5.8: 1$ and $-4.2: 1$ for «B» respectively, testifies to the significant FA correction at the expanse of $50 \%$ of the milk fat. The difference between the results of this ratio by the indices of chromatograph and mathematical program as $0.2 \%$ is an error in device indications.

\section{Conclusions}

1. Three natural vegetable oils were selected to create the blend and to combine it in further with the milk base for elaboration of milk-containing products with corrected fatty acid composition.

2. The program for calculation of blends with optimized fatty acid composition was elaborated on the base of MatLab mathematical package.

3. The maximally possible percent of replacement of the milk fat (50\%) by elaborated blend of natural vegetable oils in milk-containing products was scientifically established.

4. The reliability of the results of indices of FA composition of the studied samples «A» and «B», received by calculating method using the elaborated mathematical program, was verified by the method of gas-liquid chromatography.

5. On the base of verification of authenticity of the results of FA analysis, the offered method of blends elaboration can be recommended for the further use for creation of milk-containing products with optimized FA composition and blends with the other combination of vegetable oils.

6 . The advantage of blend method for correction of FA composition of food products comparing with biologically active additives (BAA) and medical preparation is the fact that the oils are traditional food product, which taking does not provoke complication and side effects, are significantly cheaper than BAA and the blend process can be realized by the simple and low cost technology.

7. The created blend of the vegetable oils can be further used for elaboration of the new and improvement of existing technologies of milk-containing products with optimized FA composition and also milk products of functional directionality. Especially, the most expedient is to use the high-fatty milk products (series of high-fatty milk products, cream, cream butter).

8. The use of elaborated blend in other food technologies, for example, in the oil-fat industry (production of sauces and mayonnaise of functional directionality), confectionery (production of creams and desserts of functional purpose) is prospective.

9. In further it is planned to realize the series of scientific researches for improvement of technology of sour cream product with $50 \%$ replacement of the milk fat by created blend of oils to give it the functional directionality.

\section{References}

[1] Matveeva, T., Petik, P., Fedyakina, Z., Shapovalova, I. (2013). Background of coupage oils optimal fatty acid composition. Report. Technical science chemical technologies, 1-5.

[2] Belinskaia, A., Krychkovskaia, L., Zekunova, T. (2009). The development of functional food product with a balanced composition of polyunsaturated fatty acids. Journal Technologies and equipment for food production, 6, 94-98. 
[3] Matveieva, T., Petik, P., Fediakina, Z. (2013). Mathematical justification of composition of oils blends. Eastern-European journal of enterprise technologies, 3 (6 (63)), 26-28.

[4] Smoliar, V. (2006). The concept of the ideal fat diet. Journal Problems of food, 4, 14-24.

[5] Nechaev, A., Kochetkova A. (2005). Functionality vegetable oils. Journal Oilseed industry, 3, $20-21$.

[6] Rudakova, O. (2006). Algorithm of optimization fat component of spreads. Journal Oilseed industry, $3,42-44$.

[7] DSTU ISO 5508-2001. Fats and oils of animal and vegetable. The review by gas chromatography of methyl esters of fatty acids.

[8] Rudakov, O. (2001). Development of a method of interpretation of chromatograms in the identification of vegetable oils. Journal Chemistry of vegetable raw materials, 4, 79.

[9] Chmilenko, F. A., Sidorova, L., Minaieva, N. (2010). Identification and determination of trans fatty acids in the oil industry. Journal Methods and object of chemical analysis, 3, 106-117.

[10] Khasanov, V., Ryzhova, H., Dychko, K., Kuriaeva, T. (2006). Fatty acid composition and steroids of vegetable oils. Journal Chemistry of vegetable raw materials, 3, 27-31.

[11] Yvankyn, A. (2007). Fats are composed of modern meat products. Journal Meat industry, 6, 8-13.

[12] Stepycheva, N., Fudko A. (2011). Blended oils with optimized fatty acid composition. Textbook, $27-33$. 